\title{
Effects of opioids on local anesthesia in the rat: a codeine and tramadol study
}

\section{Talita Girio Carnaval Roberta Moura Sampaio Camila Bernadeli Lanfredi Maria Aparecida Borsatti Carlos Alberto Adde}

Departament of Stomatology, Dental School, Universidade de São Paulo - USP, São Paulo, SP, Brazil.
Declaration of Interests: The authors certify that they have no commercial or associative interest that represents a conflict of interest in connection with the manuscript.

\section{Corresponding Author:}

Talita Girio Carnaval

E-mail: talitacarnaval@usp.br

htrp://dx.doi.org/10.1590/S1806-83242013000600003

Submitted: Feb 20, 2013

Accepted for publication: Jul 31, 2013

Last revision: Aug 13, 2013

\begin{abstract}
Opioids are central analgesics that act on the CNS (central nervous system) and PNS (peripheral nervous system). We investigated the effects of codeine (COD) and tramadol (TRAM) on local anesthesia of the sciatic nerve. Eighty Wistar male rats received the following SC injections in the popliteal fossa: local anesthetic with epinephrine (LA); local anesthetic without vasoconstrictor (LA WV); COD; TRAM; LA + COD; LA + TRAM; COD 20 minutes prior to LA (COD 20' + LA) or TRAM 20 minutes prior to LA (TRAM 20' + LA). As a nociceptive function, the blockade was considered the absence of a paw withdraw reflex. As a motor function, it was the absence of claudication. As a proprioceptive function, it was the absence of hopping and tactile responses. All data were compared using repeated-measures analysis of variance (ANOVA). Opioids showed a significant increase in the level of anesthesia, and the blockade duration of LA + COD was greater than that of the remaining groups $(p<0.05)$. The associated use of opioids improved anesthesia efficacy. This could lead to a new perspective in controlling dental pain.
\end{abstract}

Descriptors: Codeine; Tramadol; Anesthesia, Local; Analgesics, Opioid.

\section{Introduction}

One of the most important factors for success in dental practice is the patient's well-being. Currently, several methods are being used to control pain, and drug therapy is the most common and popular worldwide. However, the use of a single drug may not be sufficient to achieve the comfort level expected by the patient.

Pain control is important because it allows the patient to leave the clinic in maximum comfort. LA is the surgeon's first choice, because it precedes the procedure and is designed to offer comfort. However, administration of these drugs is stressful, and, in many cases, the drugs do not provide the expected comfort, especially in patients with psychological disorders, such as panic, and systemic and/or neurological disorders that hinder treatment. In this regard, some adjuvant drugs have been proposed to enhance anesthesia and analgesia, such as clonidine, diazepam, morphine, codeine and tramadol. ${ }^{1}$

Although modern LAs are effective and safe for most clinical practice, there are some patients who need more comfort. In these cases, an intense search for antinociceptive agents continues, aiming at improving nerve selectivity, promoting less motor block and lowering systemic tox- 
icity incidences. ${ }^{2}$

In regard to pain control, the literature documents attempts to find the best therapy for each procedure. As reported in recent papers, it is evident that the association of more than one drug promotes better results than following the established conventional therapies. ${ }^{3}$

Considering the association therapy concept, COD and TRAM are centrally acting analgesics. When combined with other drugs, such as painkillers and LA, they reduce the occurrence of adverse effects, while producing an equivalent or greater degree of analgesia. Certain associations have been established in the medical field such as:

- paracetamol + COD,

- paracetamol + TRAM and

- TRAM + LA.

The products of these combinations of opioids with other drugs have been shown to produce analgesic and anesthetic synergism. ${ }^{4}$

The mechanism of opioid and LA association has not been elucidated. It is known that LAs act by blocking the influx of sodium in their channels, preventing increased permeability of the ion, needed for the potential action to occur. ${ }^{5}$ Opioids act by mechanisms different from those of LAs, i.e., through specific receptor opioid pathways, or through receptors coupled to ion channels, and these receptors cause changes in cellular mechanisms and balance. ${ }^{6}$

There is recent evidence of synergism in the association of COD with paracetamol in rats, demonstrated by the Hargreaves hypernociception model, ${ }^{7}$ and in the association of diclofenac sodium in the reduction of nociception in formalin-stimulated mice. ${ }^{8}$ However, no investigations regarding the synergism of action with LAs have been published. The possibility of synergism resulting in maximum antinociception with minimal doses of active therapy is considerably attractive and particularly valuable when increased efficacy occurs without increased side effects. ${ }^{9}$

\section{Methodology}

Eighty healthy male Wistar rats, about 12 weeks old and weighing 300-350 g were selected and ac- climatized at the Animal Facility of the Oral Biology Laboratory (Universidade de São Paulo - USP, Dentistry School), in plastic cages at a temperature of $20^{\circ} \mathrm{C}-25^{\circ} \mathrm{C}$, with 12 -hour light/dark cycles, receiving food and water ad libitum. The blinded study was approved by the Research Ethics Committee of the Biomedical Science Institute (057- ICB). All the experiments took place between 8:00 a.m. and 2:00 p.m.

\section{Solution preparations}

The following solutions were used to perform the sciatic nerve block:

\section{Local anesthetic solution}

- $2 \%$ lidocaine chlorhydrate with 1:100000 epinephrine (Alphacaine $100^{\circledR}$, DFL, Rio de Janeiro, Brazil): volume, $0.14 \mathrm{~mL}$;

- lidocaine chlorhydrate with no vasoconstrictor (Lidostesim ${ }^{\circledR}$, Dentsply Pharmaceutical, Catanduva, Brazil): volume, $0.14 \mathrm{~mL}$.

\section{Codeine phosphate (Codein ${ }^{\circledR}$, Cristália, São} Paulo, Brazil)

- $30 \mathrm{mg} / \mathrm{mL}, 2 \mathrm{~mL} /$ ampule. The recommended dose of injectable COD for rats, according to the manufacturer, is $5 \mathrm{mg} / \mathrm{kg}$; thus, each rat was administered $0.05 \mathrm{~mL}$ of codeine phosphate $+0.10 \mathrm{~mL}$ of saline solution for a final solution volume of $0.15 \mathrm{~mL}$.

\section{Tramadol chlorhydrate (Tramal ${ }^{\circledR}$, Pfizer,}

\section{Guarulhos, Brazil)}

- $50 \mathrm{mg} / \mathrm{mL}, 1 \mathrm{~mL} /$ ampule. The recommended dose of injectable tramadol chlorhydrate for rats, according to the manufacturer, is $20 \mathrm{mg} / \mathrm{kg}$; thus, each rat was administered $0.12 \mathrm{~mL}$ of TRAM $+0.03 \mathrm{~mL}$ of saline solution, for a final solution volume of $0.15 \mathrm{~mL}$.

The gap time of the opioid in a LA injection was selected according to the pilot experiment. It was observed that 20 minutes was the time required for maximum decrease in the action potential amplitude for the peripheral nerve. 
Figure 1 - Experimental paradigm.

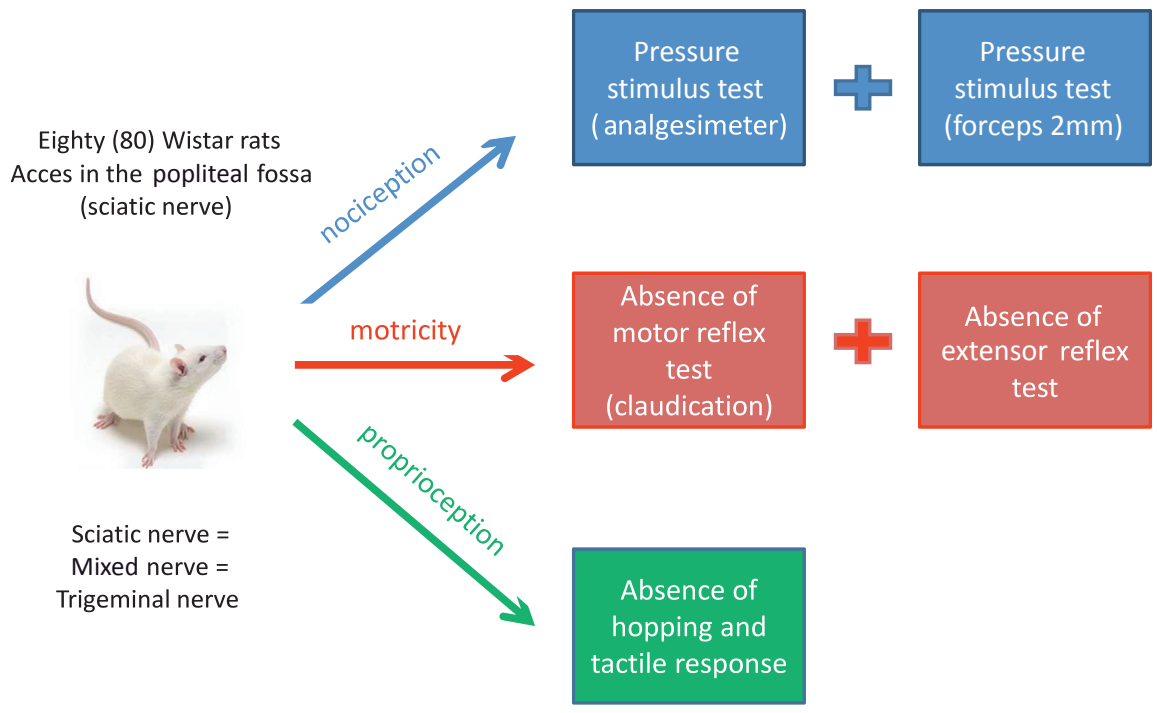

\section{Experimental procedures}

Two weeks before the experiments, the rats were randomly assigned to one of eight groups, and were exposed to preliminary experimental conditions to familiarize them with the experimenter.

The experiment involved functional steps; the paradigm is shown in Figure 1. The nerve block performed was evaluated by sensitive, motor and proprioceptive testing, and the sciatic block was conducted by an operator with access to the hind leg popliteal fossa, by SC injection. ${ }^{10}$ Thus, the experiment involved an injection procedure and a neurological evaluation, with analysis at 5-minute intervals.

Eighty rats were randomly divided into groups, and received different volumes of drugs. The abbreviations of each group represent drugs and volumes, respectively:

1. $C O D(0.05 \mathrm{~mL})$;

2. TRAM $(0.12 \mathrm{~mL})$;

3. $L A(0.14 \mathrm{~mL})$;

4. $L A W V(0.14 \mathrm{~mL})$;

5. $L A+T R A M(0.14 \mathrm{~mL}+0.12 \mathrm{~mL})$;

6. $L A+C O D(0.14 \mathrm{~mL}+0.05 \mathrm{~mL})$;

7. $C O D 20^{\prime}+L A(0.15 \mathrm{~mL}+0.14 \mathrm{~mL})$;

8. TRAM $20^{\prime}+L A(0.12 \mathrm{~mL}+0.14 \mathrm{~mL})$.

\section{Function evaluation}

The functions were evaluated according to
Thalhammer et al. ${ }^{11}$ All animals were analyzed before treatment (baseline) and at the end of the experiment, to observe if they recovered their normal function.

\section{Nociceptive response}

This was achieved through two paw withdrawal reflex (PWR) tests:

1. Withdraw reflex: applying pressure as a nociceptive stimulus using an analgesiometer (UgoBasile, Comerio, Italy) across the skin, over the lateral metatarsus, exerting and increasing linear force $(16 \mathrm{~g} / \mathrm{s})$ of up to $250 \mathrm{~g}$ (cutoff) on the rat's paw (Randall-Selitto method). ${ }^{12}$

2. Mechanical stimulation: a $2 \mathrm{~mm}$ forceps was used to exert pressure across the skin fold over the lateral metatarsus.

The paw withdraw reflex (PWR) was assessed by scores (1-3), ${ }^{12}$ where the reactions were $1=$ normal, 2 = weak (partial block), 3 = none (complete block).

\section{Motor function}

Normally, the extensor function is quantified when exerting the force required to reposition the metatarsus on the platform. The gait and spontaneous locomotive activity were evaluated by toe flexion (claudication); when the region received drugs, there was a deficit in motor function, which could 
be classified as a normal (1), partial (2) or absent (3) function.

\section{Proprioceptive function}

This was assessed by the lack of hopping and tactile-placing response. In the hopping test, the rat was kept at normal posture, where the toes of one foot were flexed with their dorsa placed on a supporting surface, and their ability to reposition their toes was evaluated as normal or abnormal.

Rats normally hop with their weight put in the direction of the movement, to avoid falling over, but when the proprioception is blocked, this response is absent (score 3 ) or classified as normal (0), slightly impaired (1) or severely impaired (2).

\section{Statistical methods}

All time duration data are shown as means \pm SD, and were compared using ANOVA and Tukey as complementary tests, because the distribution was normal and homogeneous. As for the scores, the nonparametric data were analyzed using KruskalWallis and Student-Newman-Kels as complementary tests. The significance level was 5\%.

\section{Results}

Local anesthetic associated with COD was effective in promoting a block in rats, and proved longerlasting than using COD alone, which was administered 20 minutes prior to LA $(p<0.05)$, and which provided a greater period of pain control; at the end of the experiment, all animals recovered their normal function.

The potential was verified when it caused a mean sensitive blockade lasting 36 minutes compared with only 20.5 minutes for TRAM (Figure 2). Although no significant difference was determined between these two groups ( $p>0.05)$, the only factor confirmed was the greater potency of COD (Table $1)$.

The results presented in Figure 2 suggest a groundbreaking development regarding the confirmation of synergisms, since they indicate that the $\mathrm{LA}+\mathrm{COD}$ association increased the mean duration of the sensitive block 2.6-fold in comparison with LA alone (Figure 3).

Concerning the associations, the sensitive blockade analysis confirmed the prolonged duration of a complete block in relation to LA alone. ${ }^{13-15}$ In the experimental groups, performance showed that LA + $\mathrm{COD}=\mathrm{LA}+\mathrm{TRAM}=\mathrm{COD} 20^{\prime}+\mathrm{LA}=\mathrm{TRAM}^{\prime} 0^{\prime}$ $+\mathrm{LA}>\mathrm{LA}(p<0.05)$. Moreover, the associations also showed longer block durations than LA alone in the motor and proprioceptive evaluations (Figures 4 and 5).

Thus, although the results of combinations achieved similar mean values $(p>0.05)$, COD was more promising, since a dose of only $5 \mathrm{mg} / \mathrm{kg}$ was able to achieve effects similar to $20 \mathrm{mg} / \mathrm{kg}$ of TRAM. These data are consistent with the therapeutic aim and pursuit of synergism, by obtaining maximum antinociception with minimal active dos-

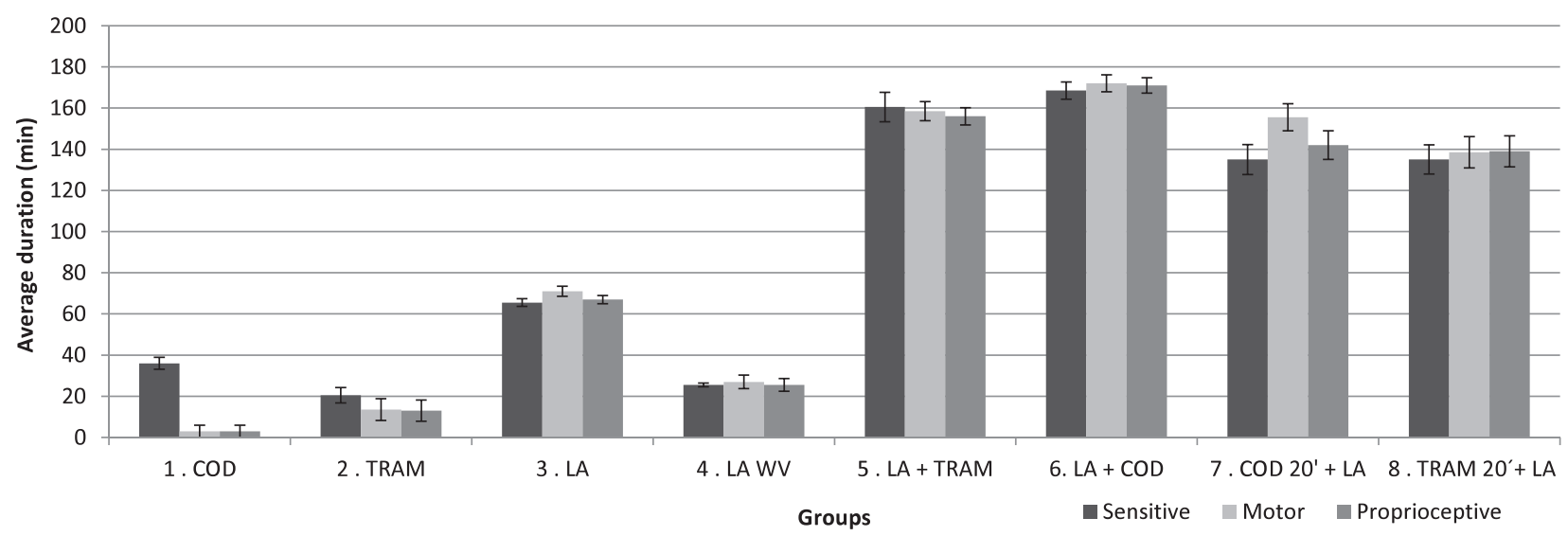

Figure 2 - Mean duration values. 
Table 1 - Description of significance.

\begin{tabular}{|c|c|c|c|c|c|c|c|c|c|c|c|c|c|c|c|c|c|c|c|c|c|}
\hline \multicolumn{8}{|c|}{ Sensitive } & \multicolumn{7}{|c|}{ Motor } & \multicolumn{7}{|c|}{ Proprioceptive } \\
\hline & 2 & 3 & 4 & 5 & 6 & 7 & 8 & 2 & 3 & 4 & 5 & 6 & 7 & 8 & 2 & 3 & 4 & 5 & 6 & 7 & 8 \\
\hline 1 & ns & $x$ & ns & $x$ & $x$ & $x$ & $x$ & ns & $x$ & ns & $x$ & $x$ & $x$ & $x$ & ns & $\mathrm{x}$ & ns & $x$ & $x$ & $x$ & $x$ \\
\hline 2 & & $x$ & ns & $x$ & $x$ & $\mathrm{x}$ & $x$ & & $x$ & ns & $x$ & $\mathrm{x}$ & $\mathrm{x}$ & $x$ & & $\mathrm{x}$ & ns & $x$ & $x$ & $x$ & $x$ \\
\hline 3 & & & $x$ & $x$ & $x$ & $x$ & $x$ & & & $\mathrm{x}$ & $x$ & $x$ & $\mathrm{x}$ & $x$ & & & $x$ & $x$ & $x$ & $x$ & $x$ \\
\hline 4 & & & & $\mathrm{x}$ & $x$ & $\mathrm{x}$ & $x$ & & & & $x$ & $x$ & $\mathrm{x}$ & $x$ & & & & $x$ & $x$ & $x$ & $x$ \\
\hline 5 & & & & & ns & ns & ns & & & & & ns & ns & ns & & & & & ns & ns & ns \\
\hline 6 & & & & & & $\mathrm{x}$ & $x$ & & & & & & $\mathrm{x}$ & $x$ & & & & & & $x$ & $x$ \\
\hline 7 & & & & & & & ns & & & & & & & ns & & & & & & & ns \\
\hline 8 & & & & & & & & & & & & & & & & & & & & & \\
\hline
\end{tabular}

$x=p<0.05 ; n s=$ not significant. Groups: 1. COD; 2. TRAM; 3. LA; 4. LA WV; 5. LA + TRAM; 6. LA + COD; 7. COD 20' + LA; 8. TRAM 20' + LA.

Figure 3 - Mean values of paw withdrawal reflex (PWR) intensity following analgesiometer nociceptive stimulus assessed over time.

Figure 4 - Values for motor reflex (claudication). (1) normal function, (2) partial function, (3) absent function.

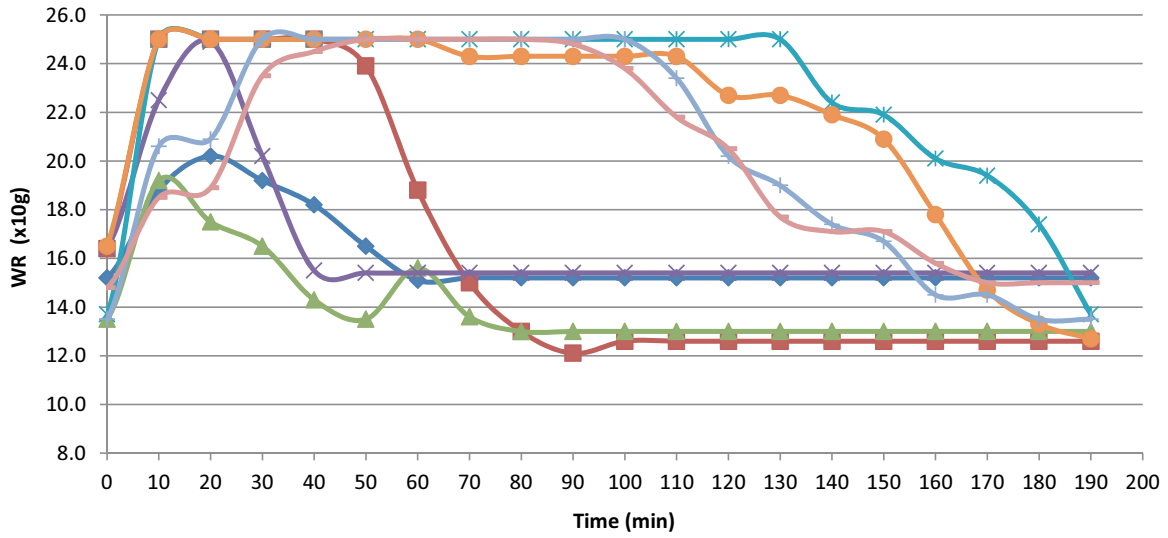

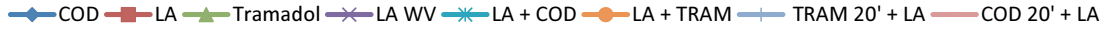

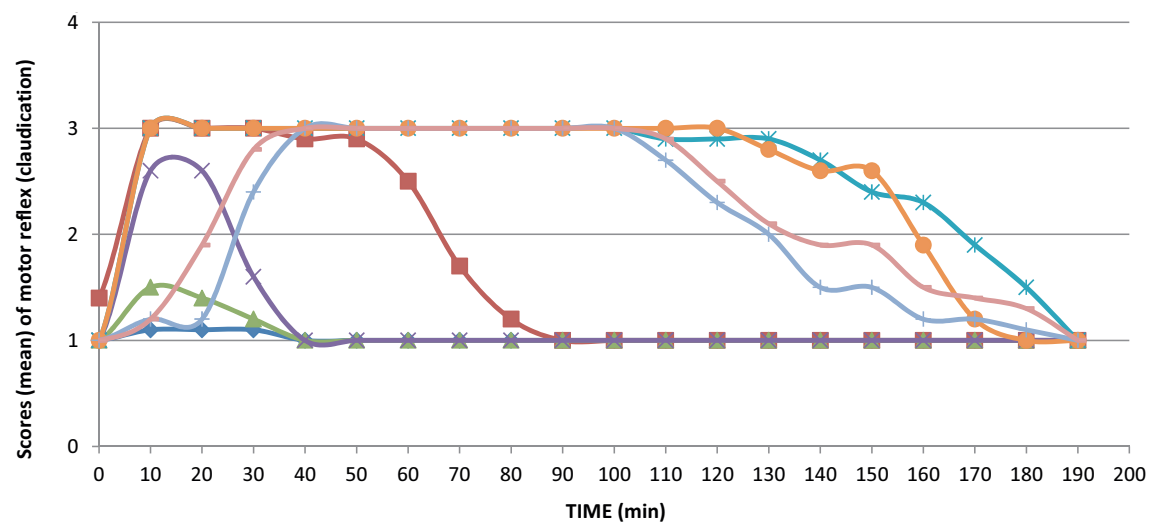

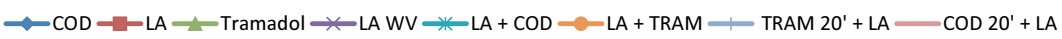


Figure 5 - Values of the proprioceptive reflex. (0) normal function, (1) slightly impaired,

(2) severely impaired, (3) absent function.

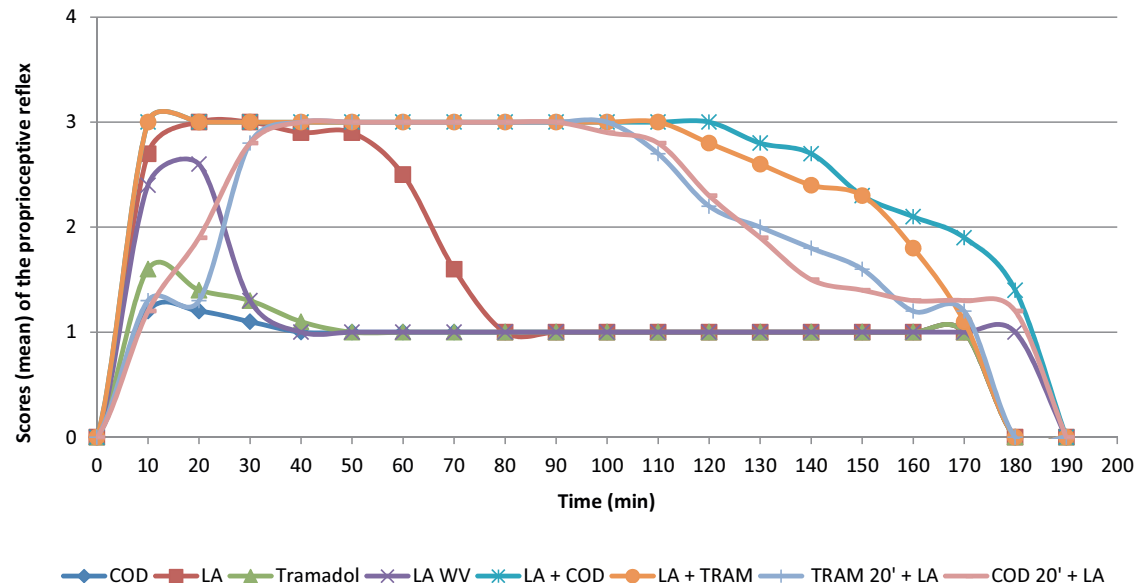

es of the drugs used, promoting increased therapeutic efficacy without major side effects. ${ }^{9}$

Regarding the dosing interval between the associated drugs to achieve sensitive blockade, it was observed that both the COD20' + LA and TRAM20' + LA groups-opioid injection 20 minutes prior to the LA-proved to be a less effective blockade than the association of LA + COD or LA + TRAM. Although a period of 20 minutes is indicated for the maximum reduction of the action potential, better activity was not achieved when COD and TRAM were injected prior to LA. This suggests that opioids presented the best sensitive block activity when injected at the same time as LA. ${ }^{16}$ We also have to consider that TRAM peaked at about 10 minutes; therefore, it will be possible to obtain different results if we use 10 minutes as a gap time in future research.

\section{Discussion}

This is the first study to evaluate the synergic effect of COD and TRAM in the duration of local anesthesia, considering nociceptive, motor and proprioceptive functions.

It is very common in dental health practice for patients to associate oral procedures with pain, and, since their experience is perceived as painful, this can lead them to avoid or delay treatment. ${ }^{17}$ This highlights the growing need for drug development and technical associations that meet patients' expectations of comfort, so that they may continue to seek good oral healthcare.

The association of local anesthetic and opioids may improve the duration of the analgesia. This is important, since the use of long-acting anesthetics, such as bupivacaine, is controversial. It can trigger an inflammatory reaction and increase postsurgical pain at the time of maximal inflammatory reaction. ${ }^{18}$

Opioid are adjuvants that prove successful in research and clinical use. Anesthetic adjuvants now represent some of the most important developments in current research in this area. ${ }^{2}$ They are considered well tolerated and have few systemic effects following peripheral administration; however, COD is also a potent opioid analgesic with a complex mechanism of action. Its performance as an analgesic on the PNS is excellent, i.e., up to twice as good as that of the CNS. ${ }^{19}$

This strong effect on the PNS corroborates evidence of synergism and demonstrates that COD could be a potent anesthetic adjuvant. In addition, considering its natural origin, low cost and availability, compared with TRAM and other relevant opioids, COD has the potential of becoming an important anesthetic adjuvant.

A study by Tsai et al..$^{20}$ stated that TRAM has some mechanism that provides a greater power differential for local anesthetic action and synergisms.

The blockade could be mediated by peripheral specific receptor or nonspecific opioid receptor actions on the cell membrane dependent on coupled receptors; however, the mechanisms of action remain unclear. ${ }^{6}$ The possibilities include stimulation of opioid-specific receptors $(\mu, \delta, \kappa)$, which according to their cell expression, could generate direct effects 
on the intracellular mechanisms that regulate transmission inside the cell through exocytotic vesicles. ${ }^{21}$

Another possibility is the action of nonspecificopioid receptors that are usually attached to cell membrane channels, where their activation is able to change the modulation ion. In fact, Rhim and Mill$\mathrm{er}^{22}$ demonstrated that presynaptic membrane activation could inhibit $\mathrm{Ca}^{2+}$ channels and induce $\mathrm{K}^{+} .23$ Alternatively, nonspecific opioid activity could occur in $\mathrm{Na}^{+}$channels, through molecular mechanisms different from those occasioned by LA. ${ }^{24}$

Regarding previous attempts at pharmacological associations, the combination of a centrally acting drug (COD) with a peripherally acting drug (LA) supports the idea that drugs with actions that involve uniting central and peripheral pathways generate onset times, activity durations and various sites of drug action that could increase the analgesic capacity; moreover, these additive and synergistic effects could occur at lower doses. ${ }^{25}$

Both COD and LA have hydroxyl groups on a molecular chain attached to the benzene ring. This is an important factor for the nervous system. ${ }^{26} \mathrm{In}$ contrast, COD is considered very potent, unlike TRAM, which has no monoaminergic interference, and which could have great beneficial action, instead of being just another opioid. ${ }^{19}$

It is known that codeine opioid molecularity is considered different in the opioid group, since it promotes greater concentration of effects on ionic membrane mechanisms and less dependency. Thus, activity in $\mathrm{K}^{+}, \mathrm{Ca}^{2+}$ and even $\mathrm{Na}^{+}$channels is possible, ${ }^{26,23,22}$ thus implying a reduction in or blockage of potential cellular hyperpolarization. ${ }^{22}$

The influx of $\mathrm{Ca}^{2+}$ and induction of $\mathrm{K}^{+}$in the nerve terminal is considered the trigger for release in synaptic cleft neurotransmitters. ${ }^{22}$ Considering the possible blockade of $\mathrm{Ca}^{2+}$ and $\mathrm{K}^{+}$channels induced by opioid codeine and tramadol, together with the

\section{References}

1. Robaux S, Blunt C, Viel E, Cuvillon P, Nouguier P, Dautel $\mathrm{G}$, et al. Tramadol added to $1.5 \%$ mepivacaine for axillary brachial plexus block improves postoperative analgesia dosedependently. Anesth Analg. 2004 Apr;98(4):1172-7. blockade of $\mathrm{Na}^{+}$channels by LAs, which keep the cell hyperpolarized, a synergistic effect would occur, resulting in nerve conduction impairment.

The stereospecificity of the properties of these opioids has been discussed for some time. Some of the separated isomers and active metabolites of COD have been determined. Despite understanding that L-codeine presents good nociceptive activity, studies have also clarified that the antitussive effect of opioids is not dependent on stereospecificity. ${ }^{27}$

Concerning TRAM toxicity in the CNS, risk of neuronal toxicity has not been reported, and in the PNS, there is also no evidence of damage. Nevertheless, the value of TRAM as an anesthetic adjunct is uncertain; therefore, caution is necessary. ${ }^{1}$ Concerning COD in the PNS, it can produce a dose-dependent and reversible decrement in motor function. ${ }^{9}$

Our results further support the concept that combinations of different analgesic modalities could reduce the incidence and severity of pain and patient anxiety. ${ }^{10}$

We also must remember that long-action solutions are available in dentistry. The use of bupivacaine, a long-lasting local anesthetic, has potential for providing anesthesia in dentistry. ${ }^{27}$

Even though the mechanisms of LA effects of opioid codeine have not been fully elucidated, an analysis of the results obtained in this study suggests that when this opioid is administered as an adjunct to the LA, it may offer many benefits to controlling pain in dental procedures.

\section{Conclusion}

The evidence of synergism and the strong effect of minimal doses of codeine emphasize its potential as an adjunct to local anesthetic. Codeine is a strong candidate for playing an adjunct role in pain control. However, studies are necessary to confirm its clinical use.

2. Wiles MD, Nathanson MH. Local anaesthetics and adjuvants-future developments. Anaesthesia. 2010 Apr;65 (1 Suppl):22-37. 
3. Hirsh I, Kaploun A, Faris G, Appel B, Shneider I, Stein A, et al. Tramadol improves patients' tolerance of transrectal ultrasound-guided prostate biopsy. Urology. 2007 Mar;69(3):491-4.

4. Raffa RB. Pharmacology of oral combination analgesics: rational therapy for pain. J Clin Pharm Ther. 2001 Aug;26(4):257-64.

5. Haas DA. An update on local anesthetics in dentistry. J Can Dent Assoc. 2002 Oct;68(9):546-51.

6. Jaffe RA, Rowe MA. A comparison of the local anesthetic effects of meperidine, fentanyl, and sufentanil on dorsal root axons. Anesth Anolg. 1996 Oct;83(4):776-81.

7. Ortiz MI, Ponce-Monter H, Fernández-Martinez E, PeresHernandez N, Macías A, Rangel-Flores E, et al. Evaluation of the interaction between acemetacin and opioids on the Hargreaves model of thermal hyperalgesia. Pharmacol Biochem Behav. 2007 Nov;88(1):47-54.

8. Jiménez-Andrade JM, Ortiz MI, Pérez-Urizar J, AguirreBañuelos P, Granados-Soto V, Castañeda-Hernãndes G. Synergistic effects between codeine and diclofenac after local, spinal, and systemic administration. Pharmacol Biochem Behav. 2003 Dec;76(3-4):463-71.

9. Mitchell D, Gelgor L, Weber J, Kamerman PR. Antihypernociceptive synergy between ibuprofen, paracetamol and codeine in rats. Eur J Pharmacol. 2010 Sep;642(1-3):86-92.

10. Truant AP. Studies on the pharmacology of meprylcaine (oracaine), a local anaesthetic. Arch Int Pharmacodyn Ther. 1958 Jul 1;115(4):483-97.

11. Thalhammer JG, Vladimirova M, Bershadsky B, Strichartz GR. Neurologic evaluation of the rat during sciatic nerve block with lidocaine. Anesthesiology. 1995 Apr;82(4):1013-25.

12. Randall LO, Sellito JJ. A method for measurement of analgesic activity on inflamed tissue. Arch Int Pharmacodyn Ther. 1957 Sep 1;111(4):409-19.

13. Pozos-Guillen A, Martinez-Rider R, Aguirre P, Perez-Banuelos $\mathrm{J}$. The effects of tramadol added to articaine on anesthesia duration. Oral Surg Oral Med Oral Pathol Oral Radiol Endod. 2006 Nov;102(5):614-17.

14. Kaabachi O, Ouezini R, Koubaa W, Ghrab B, Zargouni A, Abdelaziz AB. Tramadol as an adjuvant to lidocaine for axillary brachial plexus block. Anesth Analg. 2009 Jan;108(1):367-70

15. Mert T, Gunes Y, Guven M, Gunay I, Ozcengiz D. Comparison of nerve conduction blocks by an opioid and local anesthetic. Eur J Pharmacol. 2002 Mar 29;439(1-3):77-81.
16. Förster JG, Rosenberg PH. Clinically useful adjuvants in regional anaesthesia. Curr Opin Anaesthesiol. 2003 Oct;16(5):477-86.

17. Carr DB, Goudas LC. Acute pain. Lancet. 1999 Jun 12;353(9169):2051-8.

18. Gordon SM, Chuang BP, Wang XM, Hamza MA, Rowan JS, Brahim JS, et al. The differential effects of bupivacaine and lidocaine on prostaglandin E2 release, cyclooxygenase gene expression and pain in a clinical pain model. Anesth Analg. 2008 Jan;106(1):321-7.

19. Erichsen HK, Hao JX, Xu XJ, Blackburn-Munro G. Comparative actions of the opioid analgesics morphine, methadone and codeine in rat models of peripheral and central neuropathic pain. Pain. 2005 Aug;116(3):347-58.

20. Tsai YC, Chang PJ, Jou IM. Direct tramadol application on sciatic nerve inhibits spinal somatosensory evoked potentials in rats. Anesth Analg. 2001 Jun;92(6):1547-51.

21. Capogna M, Gähwiler BH, Thompson SM. Mechanism of $\mu$-opioid receptor-mediated presynaptic inhibition in the rat hippocampus in vitro. J Physiol. 1993 Oct;470:539-58.

22. Rhim H, Miller RJ. Opioid receptors modulate diverse types of calcium channels in the nucleus tractus solitarius of the rat. J Neurosci. 1994 Dec;14(12):7608-15.

23. North RA. Opioid actions on membrane ion channels. Handbk Exp Physion. 1993;104(1):773-97.

24. Brau ME, Koch ED, Vogel W, Hempelmann G. Tonic blocking action of meperidine on $\mathrm{Na}+$ and $\mathrm{K}+$ channels in amphibian peripheral nerves. Anesthesiology. 2000 Jan;92(1):147-55.

25. Kehlet H, Dahl JB. The value of "multimodal" or "balanced analgesia" in postoperative pain treatment. Anesth Analg. 1993 Nov;77(5):1048-56.

26. Mizuta K, Fujita T, Nakatsuka T, Kumamoto E. Inhibitory effects of opioids on compound action potentials in frog sciatic nerves and their chemical structures. Life Sci. 2008 Aug 1;83(5-6):198-207.

27. Sathorn C, Parashos P, Messer HH. Effectiveness of singleversus multiple-visit endodontic treatment of teeth with apical periodontitis: a systematic review and meta-analysis. Int Endod J. 2005 Jun;38(6):347-55. 